\title{
Lapurdum
}

LAPURDUM Euskal ikerketen aldizkaria | Revue d'études basques |

Revista de estudios vascos | Basque studies review

$21 \mid 2018$

Numéro XXI

\section{Ohar bat zer nork hurrenkeraren ezinaz euskaraz}

\section{Ricardo Etxepare}

\section{OpenEdition \\ Journals}

Édition électronique

URL : https://journals.openedition.org/lapurdum/3762

DOI : 10.4000/lapurdum.3762

ISSN : 1965-0655

Éditeur

IKER

\section{Référence électronique}

Ricardo Etxepare, «Ohar bat zer nork hurrenkeraren ezinaz euskaraz», Lapurdum [Linean], 21 | 2018,

Sarean emana----an 01 janvier 2018, kontsultatu 23 février 2022. URL: http://journals.openedition.org/ lapurdum/3762 ; DOI: https://doi.org/10.4000/lapurdum.3762

Creative Commons - Attribution - Pas d'Utilisation Commerciale - Pas de Modification 4.0 International - CC BY-NC-ND 4.0 


\title{
Ohar bat zer nork hurrenkeraren ezinaz euskaraz
}

\author{
Ricardo Etxepare \\ IKER UMR 5478, CNRS \\ ricardo.etxeparediker.cnrs.fr
}

\section{LABURPENA}

Goragotasun baldintza (Chomsky, 1973:246) NZ hitz bat baino gehiagoko galdera perpausen sintaxia gobernatzen duen hertsidura ezaguna da. Galdera perpaus batean galdera hitz bat baino gehiago bada, eta galdera hitz horiek leihatu behar badira perpausaren ezkerreko ertzera mugitzeko, mugitzen den NZ-hitza funtzioz goragokoa izango da. Honela, nork zer eratako segidak arruntak dira euskaraz, baina zer nork eratakoak ezinezkoak. Euskaraz, Reglero (2003, 2004) eta Yeong (2007) dira auzi honetaz modu xehean arduratu diren lan bakarrak. Uste dugu, zernahi gisaz, goragotasun baldintzaren baitakotzat jo daitezkeen efektuak, hala nola zer nork erako hurrenkeren ezina, ez daudela behar bezala esplikatuak euskararentzat. Lan labur honetan, euskaraz baldintza horren zeregina onenean ere zalantzazkoa dela pentsatzeko arrazoi batzuk emango ditugu. Goragotasun baldintza ezbaian jartzeko arrazoiak nork zer gisako egiturak semantikoki hurbil diren beste egitura batzuekin konparatzetik heldu dira: egitura horiek nor...bere egitura distributiboak dira, Etxeparek (2001) aztertu gisan.

\section{Gaia kokatzen}

\subsection{Goragotasunaren baldintza}

Har ditzagun ondoko perpausak ingelesez:
a. Who wrote this book?
NZ.NOM idatzi.zuen hau liburu
"Nork idatzi zuen liburu hau?"

b. What did he write?

NZ.AK zuen berak idatzi

“Zer idatzi zuen berak?" 


\section{Ricardo Etxepare}

Ingelesez, NZ-galdera perpausek NZ-hitzaren ezkerreratzea galdatzen dute. Ezkerreratze hori, aspalditik datorren ikuspegiaren arabera (Bresnan, 1972; Baker, 1970), perpausaren galderazko izaera markatzen duen tasun baten presentziarekin lotua da. Tasun hori perpausaren buru egiten duen Konplementatzaile proiekzioan gauzatua da, eta NZ-hitzaren mugidak tasun hori zilegiztatzea du helburu. Zilegiztatzea, (1a,b)-k erakusten duten bezala, edozein NZ-hitzek egin dezake. Subjektuak egiten du (1a)n, eta objektuak berriz (1b)n.

Chomsky (1973:246) bere aldetik, ondokoa bezalako pare minimoei ohartu zitzaien:
a. Who bought what?
NZ.NOM erosi.zuen NZ.AK
"Nork zer erosi zuen?"
b. *What did who buy?
NZ.AK LAG ZER erosi
“*Zer nork erosi zuen?”

(2a,b) bezalako etsenpluetan oinarriturik, Chomskyk bihurketen gaineko hertsidura orokor bat proposatu zuen, ingelesez Superiority Condition deitu zuena, eta euskaraz Goragotasun baldintza deituko duguna:

Goragotasun baldintza (Chomsky 1973:246)

Erregela batek ez ditzake $\mathrm{X}$ eta $\mathrm{Y}$ lotu ondoko egituran:

...X...[a...Z...WYV ...]...

Baldin eta erregela hori modu anbiguoan aplikatzen bazaie Z eta Y-ri, eta Z Y baino gorago badago.

Gorago egotea honela definitzen da:

(4) Z kategoria Y kategoria baino gorago dago baldin eta baldin bakarrik Z-k Y o-komandatzen badu

Goragotasun baldintzak galerazi egiten du zer galdera hitza perpausaren ezkerretara mugitzea (berez arazogabea dena), badelako tartean perpaus egituran gorago dagoen beste sintagma bat, nork NZ-hitza, zer o-komandatzen duena. (3)-ren arabera, nork du mugitzeko lehentasuna. Bestela esanda, NZ-hitz bat baino gehago dugunean perpausean, galdera tasunaren zilegiztatzea baldintza jakin batzuen barnean gertatzen da. Baldintza horiek lehenetsi egiten dute egitura aldetik gorago dagoen NZ-hitza.

Goragotasun baldintza naturalki jalgitzen da ekonomia baldintzak obeditzen dituen sistema batetik (Kitahara, 1997: 65-68). Galdera hitzen mugida Konplementzatzaile buruan dagoen NZtasun baten zilegiztatzearekin lotua dela onartzen badugu, mugimendua "laburragoa" da nork dagoen posiziotik abiatuta, zer dagoenetik abiatuta baino. Mugimenduaren luze-laburra abiapuntutik edo helmugatik neur daiteke. Abiapuntutik begiratuta, Konplementatzaileko NZ- 


\section{Ricardo Etxepare}

tasuna eta nork biltzen dituen egitura, NZ-tasuna eta zer biltzen dituen egituraren azpimultzo bat da (Hornstein, 2009), alde horretatik mugimenduak egitura zati ttipiagoa gurutzatzen du lehen kasuan bigarrenean baino. Helmugatik begiratuta, esate baterako Chomskyrena bezalako zunda-helmuga sistema batean (Chomsky 2000, 2001), NZ-zundak bere tasun balioztatu gabea balioztatzeko bidean Laguntzaile Sintagmaren baitan egiten duen bilaketan lehenago joko du nork zer baino. Zundak nork NZ-hitza aurkitzearekin batera bere ertzera erakarriko $\mathrm{du}^{1}$, nork zer ordena emanez $(5 \mathrm{a}, \mathrm{b})$. Ez dago sistema honetan, zer nork hitzordena sortzeko aukerarik.

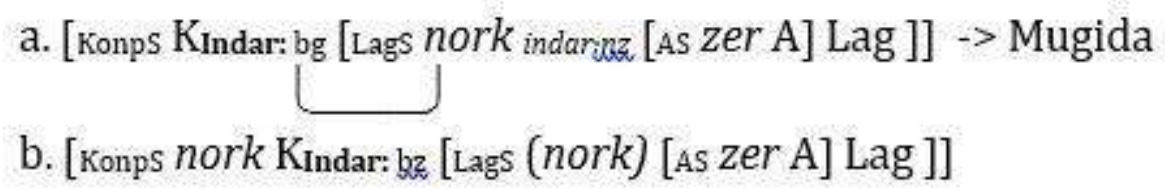

Ingelesaz bestelako hizkuntzen inguruko sintaxi lanak ugaritzen joan ahala, garbi gelditu da goragotasunaren baldintzaren hedadura ez dela orokorra: munduko hizkuntza askok baimentzen dute ingelesez edo euskaraz ezinezkoak diren (6a,b)-ren eraketa. Goragotasun baldintza orokorra ez zela erakutsi zuen lehen lana Wachowicz-ena izan zen, Chomskyrenaren ondo-ondotik argitaratua (Wachowicz, 1974). Konparatu esate baterako, euskarazko eta ingelesezko (6a,b), Errusierazko (7a,b)rekin (Wachowicz 1974: 158):
a. $\quad$ *What did who buy?
b. $\quad *$ Zer nork erosi du?
a. Kto co kupil
NZ.NOM NZ.AK erosi.du
"Nork zer erosi du?"
b. Co kto kupil
NZ.AK NZ.NOM maite.du
"Zer nork erosi du?"

Goragotasun baldintza ez da besterik gabe hizkuntza baten oinarrizko hitzordenaren isla zuzena. Batetik, NZ-hitzak bere perpausaz kanpo ager daitezke, eta horrelakoetan ere, goragotasun baldintzak manatzen duen hitzordena gordetzen dute, ezinbestean;
a. *Zer nork esan dizute erosi duela?
b. Nork zer esan dizute erosi duela?

1 bg "baliogabe" gisa ulertu behar da, bz berriz "balioztatu gisa". Indar tasunaren balioa perpaus moeta nagusiak dira (galderazkoak, deklaratiboak, inperatiboak, heiagora perpausak) ikus Rizzi, 1997. 


\section{Ricardo Etxepare}

Bestetik, galderazko egiturak perpaus diferentetako NZ-hitzak konbina ditzake (ikus orobat Rudin, 1988:452, Errumanierarentzat):

$$
\text { Nork zer esan du [Konps (zer) gertatu dela]? }
$$

(9) bezalako NZ-hitz bitako galderazko perpausean, lehen NZ-hitzak goiko perpausean du jatorria. Bigarrenak berriz behekoan (bertako subjektua da). Jatorria perpaus diferentetan duten aldetik, NZ-hitzek ez dezakete azpiko ordena isla. Ohar gaitezen gainera, bi perpausetan NZhitzak subjektu funtzioa duela. Azpiko ordenari egiten ahal zaion erreferentzia beraz alferrikakoa da kasu honetan.

\subsection{Ezkerreratze orokorreko hizkuntzak}

Euskara bezalako hizkuntzek badute zernahi gisaz ingelesak ez duen ezaugarri bat, goragotasun baldintzaren ikuspegitik problematikoa gertatzen dena. Goragotasun baldintza bi NZ-hitz edo gehiagoren artean sortzen den lehiari zuzentzen zaio. Lehia hori Konp buruko galdera tasuna zilegiztatu beharrak ekartzen du: galdera tasunaren zilegiztatzea NZ-hitz bakar baten ezkerreratzearekin egiten da. Zein NZ-hitz ezkerreratzen den, baldintzak berak erabakitzen du. Kontua da, gauzak horrela, zerk ekartzen duen euskara bezalako hizkuntzetan NZ-hitz bat baino gehiago mugitu beharra. Problema aski orokorra da, ez euskararena bakarrik. Wachowicz-ek aztertu zituen hizkuntz eslaviarretan gertatzen da (Errusiera, Poloniera), eta geroztik egin diren lan ugariek erakusten dutenez, ezaugarri tipologiko aski arrunta da (ikus Boeckx eta Grohmann, 2003:1-16).

Goragotasunaren baldintza atxiki nahirik, ikerlariek irtenbide bat aurkitu diote NZ-anitzeko galderen korapiloari. Irtenbidea bestelako mugimendu klaseak aintzat hartzea da. Hau da, goragotasuna NZ-tasunaren zilegiztatzearekin lotua baldin bada, deusek ere ez du galerazten tasun horren zilegiztatzearekin loturarik ez duten bestelako mugimenduak NZmugimenduarekin batera ager daitezen, goragotasun baldintzaren azpiko lana desitxuratuaz. Esate baterako, ezaguna da espainierak ez duela goragotasun baldintzaren ageriko efekturik erakusten (Jaeggli, 1982; baina ikus berrikiago Vicente, 2013):

$$
\begin{aligned}
& \text { a. Quién compró qué? } \\
& \text { NZ.NOM erosi.zuen NZ.AK } \\
& \text { "Nork erosi zuen zer?" } \\
& \text { b. Qué compró quién? } \\
& \text { NZ.AK erosi.zuen NZ.NOM } \\
& \text { "Zer erosi zuen nork?" }
\end{aligned}
$$

Espainolaren jokaera, goragotasun baldintzaren arabera espero genukeenaren kontrakoa, uler liteke baldin eta ohartzen bagara hizkuntza honek VSO eta VOS ordenak baimentzen dituela. VOS ordena scrambling edo irabiatze prozesu baten emaitza gisa aztertu da (Ordoñez, 1998). 


\section{Ricardo Etxepare}

Honek esan nahi du Konp buruaren NZ-zundak bere tasunarentzako jomuga bilatzen duenean, bi konfigurazio posible aurkituko dituela: (11a) eta (11b).

$$
\begin{aligned}
& \text { a. [Konps Konp }+ \text { nz [Infls Inf+ad [ads qué [ads quién (ad) (qué)]]]] } \\
& \text { b. [KonpS Konp }+ \text { nz [InflS Inf+ad [ads quién (ad) qué]]] }
\end{aligned}
$$

Lehen konfigurazioa objektuaren irabiatzearen ondorio da. Qué objektua, irabiatzearen ondotik, quién subjektuaren gaineko posizio batean batzen da. Posizio horretan, gertuago dago Konpeko NZ zundatik quién galdera hitza baino. Irabiatzea hautazko prozesua denez, galdera anizkunek bigarren konfigurazio posible bat dute, (11b)koa. Irabiatzerik gabeko konfigurazio honetan, subjektua objektua baino gorago dago, eta Konp-eko NZ-tasunetik hurbilago. Bigarren konfigurazio honek (10a) galdera egitura ahalbidetzen du. Lehen konfigurazioak, (10b) egitura. Irabiatzeak beraz goragotasun baldintzaren ageriko efektuak estaltzen ditu, goragotasun baldintza bera ukitu gabe (ikus orobat Richards, 2001: 30-32, alemanarentzat).

Beste mugimendu klase batzuk, hala nola galdegaiaren lekualdatzearekin lotuak direnak, NZmugimenduaren itxura har dezakete, goragotasun baldintzaren jomuga izan gabe. Hainbat lanek agerian ematen dute NZ-hitzen eta galdegaien portaera paraleloa, Horvath-ek (1986) eta Ortiz de Urbina-k (1989), hungarierarentzat eta euskararentzat proposatu zutenetik. Ideia hauxe da: NZ-hitz bat baino gehiagoren mugimendua ikusten dugunean, mugimendu horren motibazioak ez du zertan NZ-tasuna izan behar. Litekeena da ikusten ari garena galdegai tasun batek eragindako mugimendua izatea, ez NZ-tasun batek eragindakoa. Goragotasun baldintza NZtasunaren zilegiztatzeari dagokion baldintza hutsa bada, mugimendu klase honek ez du baldintza hori obeditu beharrik. Logika honen arabera eraikitako ezkerreratze anizkunaren tipologia bat eskeintzen dute Boskovic-en lanek (1998, 1999, 2001, 2002, 2003).

Boskovic-ek (1999, 2002) hiru hizkuntza moeta bereizten ditu NZ-hitzen mugidari dagokionean: (i) ingelesa bezalako hizkuntzak, zeinetan perpaus buruko NZ-tasunak NZ-hitz bat erakartzen duen perpausaren ertzera; (ii) Txinera bezalako hizkuntzak, zeinetan tasun horren presentziak ez duen mugimendurik eragiten; eta (iii) frantsesa bezalako hizkuntzak, non bi aukerak posible diren, kontestu sintaktikoaren arabera. NZ-hitz bat baino gehiagoren aldibereko mugimenduak (NZ-mugimendu anizkunak) ez du printzipioz loturarik galdera perpausak markatzeko beharrarekin. Aparteko parametro bat da. Goragotasuna nz-mugimendua ekonomia deribazionalaren baldintzen arabera mugatzearen ondorio da. Perpaus buruko galdera tasuna modurik ekonomikoenean asebetetzen da. Asebetetze honek mugimendurik galdetzen badu, orduan gertueneko NZ-hitza da mugitzen dena. Hortik goragotasuna. Goragotasunaren baldintza beraz NZ-mugimenduarekin lotua dago, bestela esanda, perpaus buruko nz-tasunaren zilegiztatzearekin. Gauzak horrela badira, zer esan mugimendu anizkunaz? Boskovic-en arabera, mugimendua beste arrazoi batzuengatik ere gerta daiteke, esate baterako perpausaren galdegaia edo galdegaiak markatzeko. Galdegaiak, perpaus moeta ez bezala, bat baino gehiago izan daitezke perpauseko. Ez dago beraz, printzipiozko hertsidurarik galdegai bat baino gehiago izatearen kontra. Boskovic-ek bi baldintzak honela deskribatzen ditu: 


\section{Ricardo Etxepare}

(12) a. Perpaus markatzea bultzaturiko mugimendua:

Erakar NZ-hitz bakar bat

b. Galdegaia markatzeko mugimendua

Erakar egon daitezkeen galdegai guziak perpaus ertzera

Lehen baldintzak ekonomia printzipioetarako bidea irekitzen du (e.b. erakar ezazu gertuen dagoena). Bigarrenak ez.

Bi mugimendu klase horiek nahasirik ager daitezke mugimendu anizkuna erakusten duten hizkuntzetan. Boskovic-ek serbo-kroaziera eta bulgariera konparatzen ditu, Stjepanovic-en lanean oin hartuaz (1998). Serbo-kroazierak ez du goragotasun baldintza errespetatzen (13a,b); bulgarierak berriz bai (14a,b).

\section{$\underline{\text { Serbo-kroaziera }}$}
a. Ko je sta kupio?
Nork LAG zer erosi
"Nork zer erosi zuen?"
b. Sta je ko kupio?
Zer LAG nork erosi
“*Zer nork erosi zuen?"

\section{$\underline{\text { Bulgariera }}$}
a. Koj kakvo e kupil?
Nork zer LAG erosi
"Nork zer erosi du?"
b. *Kakvo koj e kupil?
Zer nork LAG erosi
“*Zer nork erosi du?"

Zerk esplikatzen du diferentzia hau? Goragotasunak perpaus markatzearekin lotua den mugimendua salatzen badu, serbo-kroazieraz ikusten dugun mugimendu klaseak ezin du perpaus markatzearekin lotua egon, galdegaia markatzeko mugimendua izan behar da. ${ }^{2}$

2 Serbo-kroazierak ageriko konplementatzaile bat ere erakus dezake galdera perpausetan. Konplementatzaile hau agertzen denean, goragotasun baldintza azaleratzen da berriro serbo-kroazieraz (Boskovic 2002 : 354). Konparatu $(13 \mathrm{a}, \mathrm{b})$ ondoko (ia,b)rekin :

(i) a. Ko li koga voli ?

nork Konp nor maite.du

« Nork nor maite du ?» 


\section{Ricardo Etxepare}

Bulgarieraz berriz, goragotasunaren baldintza operatiboa da. Nork galdera hitzaren mugimenduak galdera tasunaren asebetzearekin lotua egon behar du beraz. Zer esan orduan zer galdera hitzaren mugimenduaz? Ohar gaitezen zer ere laguntzailearen ezkerretara mugitua izan dela. Ez da hori objektuaren jatorrizko posizioa bulgarieraz. Boskovic-en erantzuna da bigarren mugimendu hori serbo-kroazieraz ikusten dugun bera dela, galdegaia markatzeko mugimendua alegia. Nola erakus dezakegu hipotesi hau zuzena dela? Boskovic-ek etsenpluak piska bat konplikatzea proposatzen du. Eman dezagun hiru galdera hitz direla mugitu direnak, bi izan beharrean. Zer predikzio egiten dugu halako kasu batean? Lehen mugimendua NZtasuna asebetzeko baldin bada, lehen NZ-hitzak goragotasun hertsidurari obeditu behar dio. Gainerako mugimenduak galdegaiaren markatzearekin lotuak direnez, ez dugu espero bigarren eta hirugarren NZ-hitza goragotasun hertsidurak galdetuko lukeen hurrenkeraren arabera ordenatuak egotea. Predikzioa betetzen da, ondoko perpaus multzoak erakusten duen bezala (Boskovic, 2002: 365; 372):
a. Koj na kogo e pokazal kogo nork $\mathrm{P}$ nor LAG erakutsi nor "Nork nori nor erakutsi dio?"
b. Koj kogo na kogo e pokazal nork nor $\mathrm{P}$ nor LAG erakutsi "Nork nor nori erakutsi dio?"
c. *kogo koj e pokazal na kogo

(15a,b) perpausetan, subjektuari dagokion NZ-hitza da galdera tasuna zilegiztatzen duena. Ondoko NZ-hitzak bestelako arrazoiengatik mugitzen dira (galdegaia markatzea), eta mugimendu horrek ez du eskatzen goragoko NZ-hitza mugi dadin. ${ }^{3}$ (15c) ezinezkoa da, NZtasuna asebetetzeko mugituriko NZ-hitza ez baita subjektua.

\section{Goragotasun hertsidura euskaraz}

Hiru arrazoi badira pentsatzeko NZ-hitzen mugida euskaraz ez dela lotua galdera tasunekin. Lehen arrazoia, NZ-galderen sintaxiaz okupatu diren ikerlari gutiz gehienek seinalatua, da galdera hitzen portaera galdegaiena bera dela (Altube, 1929; Ortiz de Urbina, 1985). Lotura

\section{b. *Koga li ko voli ?}

Serbo-kroazierako galdera anizkunek goragotasunaren baldintza obeditzen dute baitaere mendeko galdera perpaus batetik atereak direnean. Kasu horretan, mugimenduak beheko konplementatzaile burua du lehen jomuga, eta lehen urrats honek NZ-hitzen orden erlatiboa baldintzatzen du.

3 (15a) perpausak laguntzailearen ondoko posizio batean kokatzen du azken NZ-hitza. Boskovic-ek erakusten du azken NZ-hitz horren posizioa Forma Fonologikoan behartua dela (beheko kopiaren gauzatze fonologikoa da), fonologikoki berdinak diren bi NZ-hitzen segida saihesteko. 


\section{Ricardo Etxepare}

hori ez da harritzekoa kontuan harturik galdegaien eta galdera hitzen semantika aski hurbil direla (Rooth, 1985, 1990 esate baterako), euskarazko galdegai terminoak berak salatzen duen moduan, bestalde. Erreza da galdera hitzen portaera galdegaien sintaxira ekartzea. Nekezagoa berriz alderantzizkoa egitea. Hala galdegaiek nola galdera hitzek alternatibak adierazten dituzte. Hori da bi operatzaile moeta horiek partekatzen dutena. Partekatzen dutenetik kanpo gelditzen da galdera tasuna, NZ-hitzek bakarrik daukatena. Horrenbestez, galdera hitzek eta galdegaiek erakusten duten portaera sintaktiko paraleloa elkarrekin erakusten duten galdegai izaerari egotzi behar zaio. Galdegaiek posizio jakin bat betetzen badute perpausean, galdera tasuna kanpoan uzten duena, mugimendua posizio horretara da. Beste hitzetan esanda, euskaraz, NZ-tasunak, ingelesez ez bezala, ez du zilegiztatua izateko NZ-hitza erakarri behar. Diferentzia hau naturalki segitzen da zunda-jomuga sistema batetik (Chomsky 2000), zeinetan zilegiztatzeak ez du baitezpada mugimendurik galdetzen. Komunztatze operazioa nahikoa da horretarako:

\section{(16) [Konps Konp+nz [Galdegais NZ-hitza Gald [Infl ...(NZ-hitza)...]] (Komunztatu)}

Euskaraz, beraz, Boskovic-ek serbo-kroazierarentzat proposatzen duen bezala, galdegai mugimendua izango genuke, eta ez galdera tasun batek eragindako mugimendua. Predikzioa, galdera anizkunen esparrura itzuliaz, da euskarazko galdera anizkunek ez diotela goragotasunaren baldintzari obeditzen. Predikzioa partez baizik ez da betetzen. Konpara ditzagun ondoko bi perpausak:

$$
\begin{aligned}
& \text { a. } \quad \text { Nor nork ikusi du? } \\
& \text { b. } \quad \text { Zer nork ikusi du? }
\end{aligned}
$$

(17a)-k goragotasun baldintza bortxatzen du, eta perpausa onargarria da. (17b)n baldintza beraren bortxatzeak perpausa onartezina egiten du. Biziduntasunaren hierarkiarekin loturiko efektuak ezagunak dira beste hizkuntzetan, esate baterako Bulgarieraz (Rudin, 1986; DukovaZheleva, 2010:85-86). Interesgarria dena da (17a)-k goragotasunak eskatuko lukeenaren kontrako ordena erakusten duela. Boskovic-en tipologiari jarraikiko bagintzaio, euskara Errusierarekin parekatuko genuke, NZ-mugimendurik gabeko hizkuntza gisa. NZ-hitzak euskaraz galdegaiak lirateke honen arabera. Bulgarieraz, Errusieraz ez bezala, (17a) ez da posible.

Bada hala ere galdegaiaren sintaxian Boskovic-en tipologiarekin gaizki uztartzen den ezaugarri bat bederen. Euskarazko galdegaiak, NZ-hitzak alde batera uzten baditugu, funtzioaren araberako orden hertsia erakusten dute. Bestela esanda, galdegaia euskaraz, Bulgarieraz galdera tasuna bezala portatzen da. Ez da naturalki ateratzen euskaraz galdegai bat baino gehiagoko perpaus bat osatzea. Osatzea posible den heinean, hitzordenak goragotasun baldintzak gobernatua dirudi: 

a. JONEK MIREN gonbidatu du, ez AITORREK ANE
b. *MIREN JONEK gonbidatu du, ez ANE AITORREK

Hitzordena bera da galdegaiak perpausetik kanpora mugitzen baditugu:
a. JONEK MIREN esango nuke gonbidatu duela, ez AITORREK ANE
b. *MIREN JONEK esango nuke gonbidatu duela, ez ANE AITORREK

Gauzak horrela badira, ez dago garbi zergatik (17a) bezalako perpaus bat posible den euskaraz. Hau da, foko operatzaileei goragotasun baldintza ezartzen bazaie, ez dago garbi zergatik (17a) onargarria den euskaraz. Aterabide posible bat da suposatzea euskaraz NZ-tasuna eta galdegai tasuna, biak inplikatuak egon daitezkeela galdera anizkuneko egitura batean, Boskovic-ek Serbo-kroazierarentzat proposatzen duen bezala. Hipotesi honen arabera, lehen galdera hitza NZ-tasunaren zilegiztatzeko mugitzen da, eta bigarrena galdegai tasun bat zilegiztatzeko. Tasun horiek ez dira elkarrekin mintzatzen, eta zeinek bere aldetik erakartzen dute NZ-hitz bat, elkarren arteko lehiarik sortu gabe. Honek esplika dezake zergatik euskaraz, galdera anizkunek ez duten baitezpada NZ-hitz guzien mugimendua behartzen:
a. Nork erosi du zer?
b. Zer erosi du nork?

(21a,b) egiturek NZ-hitz bakar baten mugimendua erakusten dute. Posibilitate bat da bigarren NZ-hitza, galdegai gisa markatua, in-situ zilegiztatua izatea, azentuaren bitartez. NZ-hitzak elkarren lehian ez daudenez, ez dago goragotasun auzirik. Honen arabera, euskaraz bi tasun, NZ-tasuna eta galdegai tasuna, dira NZ-hitzen mugimendua eragiten dutenak.

Honen bidetik uler liteke agian zergatik euskara, bulgariera eta serbo-kroaziera bezala, NZirlarekiko sentibera den. Sentiberatasun hori izendatuki galdera tasunari lotua da gainera, ez NZ-tasun orokorrago bati. Jakin bezalako aditz baten mendekoa (22a,b) eta galdetu aditzarena (23a,b) ez dira berdin portatzen irla efektuak sorrarazteko orduan (ikus Suñer, 1993 bi predikatuen galdakizun semantiko desberdinez; Lahiri, 2002):
a. Nork ez dakizu zer erosi duen?
b. Zer ez dakizu nork erosi duen?
a. *Nork galdetu dizute (ia) zer erosi duen?
b. *Zer galdetu dizute (ia) nork erosi duen?

Jakin aditzak ez du lexikoki galderarik hautatzen. Galdetu aditzak bai. Ez gara beraz NZmorfologiari loturiko tasun batez ari, baizik eta perpausa galdera gisa markatzea posible egiten duen tasunaz. 


\section{Ricardo Etxepare}

(17a) ongi lotzen bada galdera anizkunak tratatzeko bide honekin, ez daiteke gauza bera esan (17b)-z. Galdera-hitza eta galdegaia ez badira elkarren arteko lehian, zergatik aurkitzen dugu goragotasun efektu bat (17b)-n?

$$
\text { b. *Zer nork ikusi du? }
$$

Analisi bide beretik joaz, (17b)-n lehen NZ hitza (zer) galdera tasuna zilegiztatzeko mugitu da. Bigarrena berriz (nork) galdegai tasun batek eraginda mugitzen da. (17b)rentzat biziduntasun hierarkian oinarrituriko goragotasun baldintza berezi bat formulatu beharko genuke, bizigabebizidun ordenak galerazten dituena, Bulgarieraz aurkitu denaren antzekoa. Efektu horrek berak esplikatuko luke (24a,b)-ren arteko kontrastea:

(24) (fobia bereziak dituzten horiez ari garela)

a. Zerk nor/zein izutzen du zehazki? (Oihartzun galdera)

b. Nor/zein zerk izutzen du zehazki?

(24a) aurretik emandako informazioa argitzeko galdera da, goranzko intonazioarekin bukatzen dena. (24b), kontestu egokian, aurretik eman gabeko informazio elementu batez galdetzeko erabil daiteke, eta ez da baitezpada oihartzun galderen seinale den goranzko intonazioarekin bukatzen.

Ikuspegi honen arabera, euskara Serbo-kroaziera bezalakoa litzateke, biziduntasun hierarkiaren baitan kokatu behar diren erantsizko baldintza batzuekin. Logika honek hala ere, badu nabarmena den erren bat: zeren gainean operatzen du biziduntasun hierarkiak? NZ-hitz bakoitza bere aldetik mugitzen bada, lehena galdera tasun bat zilegiztatzeko, bigarrena galdegai tasuna tarteko dela, zergatik eratzen da zein bere aldetik mugitzen diren elementu horien arteko hierarkia bat? Are gehiago hierarkiak NZ-hitzen kokapen erlatibo hutsari erreparatzen badio, zergatik ez da ezartzen bietako bat beheko lekuan gelditzen denean?

$$
\text { Zer erosi du nork? }
$$

Ondoko atalak xehekiago erakutsiko duen moduan, NZ-hitzen orden erlatiboari galderazkoak ez diren egituren ikuspegitik heltzeak, arazoaren tratamendu egokiagoa ahalbidetzen duela uste dugu. Goragotasunari egotzi dizkiogun efektu berberak galderazkoak ez diren egituretan aurkitzen baditugu, seinale garbia da okerreko bidetik jo dugula zer nork hurrenkeren ezina esplikatzeko ahaleginean.

\section{Nor...bere... egiturak}

Euskarak baditu, erlazio distributiboak adierazteko baliatzen dituen bitarteko gramatikalen artean, ondokoak bezalako egiturak (Etxepare, 2002; agertzekoa):

a. Nork bere ama maite du 


\section{Ricardo Etxepare}

b. Athletic-eko 11 jokalariak zelaira atera dira. Zein bere tokian jarri da.

(26) bezalako egiturak NZ-hitzen gainean eraikiak dira. Alde honetatik bereizi egiten dira zenbatzaile lexiko baten bitartez adierazten diren egitura distributiboetatik:

(Gizon) bakoitzak bere ama maite du

Egitura hauek galdera egituretatik bereizten dira ere: ez dute hitzorden bera erakusten, eta ez dute galderazko egiturek duten esanahi ez intonazio bera. Galdera hitzak, galdera perpausetan, aditzaren aurre-aurrean egon behar du (28a). Distribuzio egituran, banagaia edo banatua dena da aditzaren aurreko galdegai posizioan agertzen dena (28b):

(28) a. Nork maite du bere ama?

b. Nork bere ama maite du

Egitura hauek badituzte, aipagai dugun aferari dagokionez, ezaugarri jakingarri zenbait. Tartean, zer nork hurrenkeraren ezinari begira axolazkoa den bat: ez dira posible zer galdera hitzarekin (Etxepare, 2001). ${ }^{4}$

(29) *Zer bere lekuan jarri dugu

\section{Galdera anizkunez berriro}

\subsection{Parekatze galderak eta egitura distributiboak: paralelo}

\section{semantikoak}

NZ-hitzen bitartez bideratzen den distribuzio moeta honek antzekotasun harrigarriak ditu NZhitzen eta zenbatzaileen arteko interakziotik sortzen den mendekotasun funtzionaleko kasuekin. Chierchiak erakusten duen bezala (1993), Groenendijk eta Stokhof (1984) eta Engdahl-en (1986) lehenagoko lanak gogoratuaz, (30A) bezalako galdera batek (30B) erantzuna izan dezake.

(30) A: Who does everyone love? (Nor maite du mundu guziak?)

B: His mother (Bere ama-norberarena alegia)

Erantzun moeta horretan oin harturik, Chierchiak proposatzen (30A) bezalako galderetan, NZhitzak bi atal dituen aztarna edo kopia konplexua uzten duela. Kopia horrek badu argumentuari

4 Euskarazko Ereduzko Prosan zer bere hurrenkeren xerka egindako bilaketak ez du ale bakar bat ere ekarri. Ezta Euskarazko Korpus Historikoan egindakoak ere. 


\section{Ricardo Etxepare}

dagokion aldagai bat -(30B)ko izenordainak errepresentatua- eta aldagai funtzional bat, kasu honetan norbaiten ama izateari dagokiona. Argumentuari dagokion aldagaia zenbatzaileak uztartzen du. Funtzioari dagokiona berriz, NZ-hitzak. Chierchiak bi ataleko egitura hori baliatzen du goragotasun baldintzaren eite duen ondoko kontrastea esplikatzeko: zenbatzaile bat eta galdera hitz bat biltzen dituen perpaus batean, NZ-galdera bada funtzioz goragokoa, erantzun funtzionala ez da posible:
A: Who loves everyone? (Nork maite du mundu guzia?)
B: His mother? (Bere amak -*norberarenak alegia)

Chierchiak erantzun funtzionalaren ezina gurutzatze baldintza ahularekin lotzen du. ${ }^{5}$ Baldintza honek xedatzen du zenbatzaile batek ez dezakeela aldagai gisa har bere ezkerretara dagoen izenordain posesibo bat. NZ-hitzaren azpiko egitura Chierchiak proposatzen duen bezalakoa bada (barnean izenordain bat gordetzen duena), orduan operadore-aldagai konfigurazioa gurutzatze baldintza bortxatzen duen bat da, aldagaia zenbatzailearen ezkerrean ageri baita:

$$
*_{\text {pro }} \mathrm{NZ} \text {...everyone } \text { ev }_{\text {.. }}
$$

Chierchiak forma logikoaren esparruan kokatzen du NZ-hitzaren egitura konplexua. Hornsteinek (1995) egitura hori sintaxian gauzatua dela defendatzen du. Hots, NZ-hitzek, erantzun funtzionala ahalbidetzen dutelarik, egiazki bi atal sintaktiko dituzte: bata izenordaina, eta bestea funtzio bat, izenordain horrek denotatzen dituen norbanakoetatik funtzioaren errestrikzioak denotatzen dituen norbanakoetarakoa. Bi izenki biltzen dituen funtzio hori, sintaktikoki, azpiko egitura posesibo baten bitartez gauzatzen da. NZ-hitzaren forma sintaktikoa beraz, (31B)rena da. Ohartzen baldin bagara, forma hori distribuzio egituren banagaiarena bera da. Euskarazko NZ-distribuzio egiturek erakusten dituzten ezaugarri berezien artean dago banagaia era horretakoa izan daitekeela bakarrik. Bakoitz zenbatzaile lexikoak ez bezala, NZ-hitzek bideraturiko distribuzioak banagai funtzionalak galdetzen dituzte. Bestela erranik, euskarazko NZ-distribuzio egiturek erantzun funtzionalen forma logikoa erakutsian uzten dute. Etxepareri $(2001,2020)$ jarraituz, NZ-hitza distribuzioa eragiten duen buru funtzional bati lotzen zaio (Distribuzio Sintagma, ikus Brody eta Szabolcsi, 2003; Szabolcsi 2010). Banagaia (norbanakoen arteko funtzio bat denotatzen duena) buru horren ondoan den galdegai posiziora mugitzen da (Banagai Sintagma):

$$
\text { b. [DistrP NZ-hitza } \operatorname{Distr}^{0}{ }_{\text {[Banagais }} f(I S) \operatorname{Ban}^{0}[\text { InfS...]]] }
$$

Chierchiaren arabera (1993), irakurketa funtzionalak badu bertsio estensional bat, zeinetan funtzioa bikote-zerrenda baten gisan aurkezten ahal den: horrela gauzatzen den erantzunari

5 Horrela itzultzen dut ingelesezko weak crossover condition dermioa. 


\section{Ricardo Etxepare}

parekako erantzuna deituko diogu (pair-list ingelesezko terminologian). Irakurketa funztionalaren bertsio estensionala aipatzen dugunean, esan nahi dugu (31B)ko erantzuna uler daitekeela jendeen eta haien amen arteko parekatze konkretuen laburbilduma gisa. Diskurtsuaren unibertsoan hiru seme-alaba baditugu (Jon, Mikel, eta Ane) eta hiru ama (Miren, Jasokunde eta Sonia), (31B) erantzuna (34B)ko parekatzeen sintesi gisa eman daiteke:
A: Who does every youngster love? (Nor maite du gazte bakoitzak?)
B: Ane alaba $_{\text {loves Miren }}$ ama, Jon semea $_{\text {Jasokunde }}$ ama and Mikel semea $_{\text {Sonia }}$ ama

(34B) erantzun funtzionalaren orri zabalgarritzat jo badezakegu, pentsa liteke parekako erantzunak ere antzeko azpiko egitura distributibotik segi daitezkeela.

Gauzak horrela, zentzuzkoa ematen du galdetzea parekako erantzunek ahalbidetzen dituzten galdera moetak ez ote diren egitura distributibotik zuzenean erakarritako erantzunak. Alegia, parekako erantzunak baimentzen dituzten galdera anitzeko perpausek azpian egitura distributibo bat duten, euskarazko NZ-egitura distributiboen berbera. Horren aldeko ebidentzia distribuzio egituren eta parekako erantzunek ahalbidetzen dituzten galderen artean ikusten diren paralelotasunetan aurki daiteke. Egitura biek partekatzen dituzten ezaugarri horiek ondoko atalean tratatzen dira.

\subsection{Egitura mailako paraleloak}

NZ-bat oinarrian duten egitura distributiboek, zenbatzaile distributibo lexikoek ez bezala, banagaiaren aurreratzea eskatzen dute galdegai posizio batera. Konparatu hartara $(35 a, b)$ eta (36a,b):

a. Nork bere zaldiak uste du [ (bere zaldiak) irabaziko duela]

b. *Nork uste du [bere zaldiak irabaziko duela] (egitura distributibo gisa)

a. ?Ikusle bakoitzak bere zaldiak uste du irabaziko duela

b. Ikusle bakoitzak uste du bere zaldiak irabaziko duela

Banagaiaren aurreratzeak, galdegai egiturekin ohikoa den bezala, pied-piping fenomenoa eragin dezake. (37) etsenpluan, banagaia (bere zaldiak) menpeko perpaus batean txertatua dago, eta perpaus hau bere aldetik, denborazko aditzlagun baten parte da. Egitura osoa da galdegai posiziora mugitzen dena, beste menpeko perpaus bat gurutzatuaz:

(37) Nork [DenbAL[Konps bere zaldiak irabazten duela] ikusten duenean $]_{i}$ esan du _i txalotuko duela

Parekako galderek antzeko errestrikzioak erakusten dituzte: bigarren NZ hitza berez mugi daiteke aditzaren aurreko posiziora, edo txertatua dagoen egitraren pied-piping-a eragin: 
a. Nork nork uste du [ (nork) irabaziko duela]]?

b. Nork [DenbAL[Konps nork irabazten duela] ikusten duenean] esan du txalotuko duela?

Eman dezagun ( $38 \mathrm{~b}$ ) esana izan den kontestuak biltzen dituela zaldi andana bat eta zaldi horien alde apostu egin duten ikusleak. Kontestu horretan, honelako erantzun bat posible da euskaraz:

Jonek esan du “Goiz-Argi”-k irabazten duela ikusten duenean txalotuko duela;

Aitorrek, "Tximista Gorri"-k irabazten duela ikusten duenean egingo duela, eta Mirenek berriz "Urrutiko Trumoi”-k irabazten duela ikusten duenean.

Egiturak, bistan da, sinpleagoak izan daitezke. Behar duguna da banagai gisa agertzen den NZhitza galdegai posiziora mugitzea parekako erantzunak inplikatuak direnean. (40a,b)-k azpiko egitura bera izango lukete (40c), galdera tasuna salbu:
a. Nork bere ama maite du
b. Nork nor maite du?
c. [DistrP Nork Distr $^{0}$ [Banagais nor/bere ama $\operatorname{Ban}^{0}$ [Infs maite du]]]

Banagaia nahi bezain egitura konplexuan txertatua izan daiteke. Banaketa giltzaren konplexutasuna, ordea, bereziki hertsiak diren mugen barnean kokatzen da. Distribuzio egituren ezaugarrietako bat da galdera egiturekin ez bezala, distribuzio giltza NZ-hitz biluzia bakarrik izan daitekeela, kasu markak barne:

a. Noren lagunak gonbidatu gaitu bere festara?

b. *Noren lagunak bere festara gonbidatu gaitu (Distributiboa)

Parekako erantzunen azpian distribuzio egiturak baldin badaude, esperoko genuke horrelakoetan lehen NZ-hitzak konplexutasun minimoa izatea. Predikzioa betetzen da. Neretzat, (42a)k ez dezake parekako erantzunik izan: ${ }^{6}$

\footnotetext{
6 Distribuzio giltzaren gaineko hertsidura honek zalantzazkoa egiten du parekatze galderak Q-partikula berezi baten operazioen bitartez analizatzea (Cable, 2010 ; Chernova, 2014). Cable-ek galdera egiturak analizatzeko egiten duen proposamenaren alderdi interesgarrietako bat da pied-piping fenomenoari ematen dion aterabide naturala. Printzipioz, Q-partikula NZ-hitza berari edo hura biltzen duen egitura bati lotu egiten zaio. Q-partikularen batzea irla baten kanpotik gerta daiteke (hau da, NZ-hitza biltzen duen irlarekin batu daiteke), eta horrela Qpartikularen mugimenduak irla osoak berekin eraman ditzake (pied-piping delakoa). Euskara pied-piping hizkuntza da. Q-partikula baten presentziak printzipioz NZ-hitz hutsa baino egitura konplexuagoak ahalbidetu behar lituzke, baina parekatze galderetan distribuzioaren giltza egiten duen NZ-hitzak ezin du egitura konplexuago baten barnean txertatua egon. Asumitzen dut Q-partikula bidezko analisia ez dela bide egokia parekatze galderak aztertzeko euskaraz.
} 


\section{Ricardo Etxepare}

Noren lagunak nor ikusi du?

Distribuzio giltza gisa ari den NZ hitzak kasu markak har ditzake, baina ez postposizioak, (43a) etsenpluak erakusten duen bezala. (43b) erakusten duenez, galdera hitzek ez dute errestrikzio bera erakusten:
a. *Norentzat bere oparia erosi dugu (cf. Bakoitzarentzat bere oparia erosi dugu)
b. Norentzat erosi duzue oparia?

Galdera anizkuna osatzen badugu baina, postposiziodun NZ-hitzak ez du ahalbidetzen parekako erantzunik. ${ }^{7}$ (44) perpausean, pare bakarraz galdetzen da.

\section{Norentzat zer erosi du?}

NZ-distribuzio egiturek euskaraz hertsidura gogorrak ezartzen dituzte banagaiaren izaera semantikoan. Etxeparek (agertzekoa) erakusten duen bezala, banagaia mugatua izan behar du euskaraz, edo bederen espezifikoa. Bestelako banagaiak, zenbatzaile ahulak buru dituztenak, ez dira posible banagai gisa:

Kontestua: liburu azoka batean, bildutako idazleek publikoarentzat liburuak sinatzen ari dira. NZ-hitzak idazleei egiten die erreferentzia.
a. Nork [bere liburua] sinatu zuen
b. Nork [bere liburu guztiak] sinatu zituen
c. Nork [bere liburu gehienak] sinatu zituen
d. Nork [bere liburu bakoitza] sinatu zuen
e. Nork [bere liburu bakarra] sinatu zuen
a. *Nork [bere liburu asko] sinatu zituen
b. *Nork [bere liburu gutxi] sinatu zituen
c. *Nork [bere liburu pila bat] sinatu zuen
d. *Nork [bere libururen bat] sinatu zuen
e. Norki $_{\mathrm{i}}\left[\mathrm{bere}_{\mathrm{i}}\right.$ bi liburu baino gehiago] sinatu zituen

\footnotetext{
7 Lan honek ez du barrentzen prosodia eta galdera egituren arteko loturan, baina (44a), eta orohar parekako erantzunak ahalbidetzen dituzten galdera anizkunetako lehen NZ-hitzak (banaketa giltzak) nabarmenki ezinezkoak dira galdera anizkunak galdera sinpleen ohizko intonazioa badu, goranzko kurba melodikoarekin perpaus bukaeran.
} 


\section{Ricardo Etxepare}

Parekako erantzunak ahalbidetzen dituzten galdera anizkunak azpiko egitura bera baldin badute, espero dugu antzeko hertsidurak erakustea parekako erantzunari dagokionez. Predikzioa betetzen da, modu zorrotzean gainera: nere belarrietan, (48a-e) ezinezkoak dira.
a. Nork noren liburuak irakurri ditu ?
b. Nork noren liburu guztiak irakurri ditu?
c. Nork noren liburu gehienak irakurri ditu ?
d. Nork noren liburu bakoitza irakurri du ?
e. Nork noren liburu bakarra irakurri du ?
a. *Nork noren liburu asko irakurri ditu?
b. *Nork noren liburu bat baino gehiago irakurri du?
c. *Nork noren liburu pila bat irakurri du ?
d. *Nork noren libururen bat irakurri du ?

Bigarren NZ-hitza aditzaren ondoko posizioan badago, (48a-e)ko perpausak posible bilakatzen dira.
a. Nork irakurri ditu noren liburu asko? (Pare bakarra)
b. Nork irakurri du noren liburu bat baino gehiago? (Pare bakarra)
c. Nork irakurri du noren libururen bat? (Pare bakarra)
d. Nork irakurri ditu noren liburu pila bat? (Pare bakarra)

(49a-d) perpausek ez dute parekako interpretaziorik. Hau da, (49c)ren erantzun posible bat (50a) da, baina ez (50b):
a. Jonek, (irakurri du) Ur Apalategiren azkena
b. \#Jonek Itxaro Bordaren azkena, Mikelek Ur Apalategiren azken aurrekoa, eta Anek Eñaut Etxamendiren lehena

\subsection{Zer nork hurrenkerak}

Parekatze galderek distribuzio egiturekin erakusten dituzten antzekotasunen haritik tiratuaz, lan honen izenburutzat eman dugun fenomenora iristen gara. Ikusi dugu badirela arrazoi anitz, zer nork hurrenkeren ezina euskaraz goragotasun baldintzaren baitan ez emateko. Distribuzio egiturek hurrenkera horren arazotasuna esplikatzeko bestelako irtenbide bat ematen digute. NZbidezko distribuzio egiturarik ezin da altxatu euskaraz zer NZ-hitzaren gainean:

$$
\text { *Mundu honetan, zerk bere saria du }
$$

(51) guziz ulergarria da euskaraz, baina ez da perpaus gramatikala. Zer NZ-hitza ez badaiteke distribuzio egituretako giltza izan, eta parekako interpretazioa duten galdera anizkunen azpian NZ-distribuzio egitura bat badago, ez dugu galdera moeta horren baitan hurrenkerarik aurkituko 


\section{Ricardo Etxepare}

zer NZ-hitza lehen elementu gisa duenik. Distribuzio egituretan zer-en ezin hori zeri zor zaion laburki azalduaz bukatzen dut lan hau.

Zer eta nor/zein izenordainen arteko desberdintasuna, distribuzioa sustatzen duten kontestu semantikoetan, ez da ez-ohikoa NZ-bidezko distribuzioaren alorrean. Japonierazko nani "zer" esate baterako, ez daiteke -mo- partikularekin lotu balio unibertsal eta distributiboarekin, japonierazko nor eta zein izenordainekin gertatzen den bezala (Yatsushiro 2009:143):

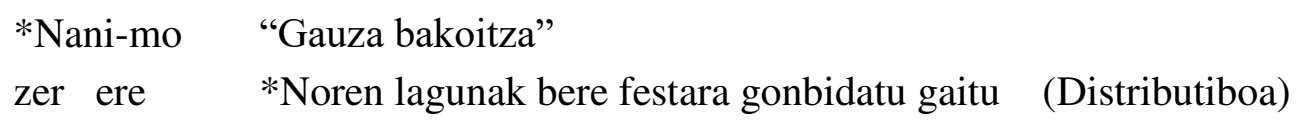

Espainolez, cada zenbatzailea quién "nor" eta cuál "zein" NZ-izenordainekin batu daiteke, balio unibertsal eta distributiboarekin (CREA korpuseko etsenpluak):
a. A cada quién lo suyo
b. ...metiendo cada cual la cuchara en la caldera

Baina ezin da gauza bera egin qué izenordainarekin:

$$
\text { *Cada qué }
$$

Honetan ere, euskarazko NZ-bidezko distribuzioa eta bakoitz zenbatzaile distributibo lexikoa ez dira berdin portatzen. Euskarazko idatzizko erregistro jasoetan aurkitzen ahal dira zer eta bakoitz-en konbinazioz sorturiko zenbatzaile konplexuak (Euskararen Ereduzko Prosa korpusetik):
a. Dena ondo, zer bakoitza bere tokian (Gerrako ezbeharrak, Arrinda 1988)
b. Ankisek...zer bakoitza banaka azaltzen dio (Ibiñagabeitia, Ilias-ena itzulpena, 1962)

Diferentzia bat, Japonierazko NZ-bidezko kuantifikazioaren eta euskarazko bakoitz bidezko kuantifikazioaren artean, zenbatasunaren presentzian dago, zehazkiago, numeroaren presentzian. Japonierazko zenbatasun egiturak NZ izenordain bat eta operadore logiko baten konbinaketaren bitartez eratzen dira. Pentsatzekoa da operadore logiko horiek ez dutela berez numero gramatikalik galdetzen (besteak beste maila proposizionaleko egiturak ere batzen dituztelako, eta hauek ez dute numerorik erakusten). Bakoitz oinarri duten euskarazko egiturek aldiz, (55a,b) kasu, numeroa dakarte, artikuluaren presentziaren ondorio gisa eta beren izaera distributiboak galdetzen duen zenbagarritasunaren aldetik. Kontuak horrela badira, lotura bat egin dezakegu ezaugarri honen eta distribuzio egituretan zer eta nor/zein izenordainen artean gertatzen den bereizketa garbiarekin. Euskarazko nor eta zein numero gramatikaldunak dira, laguntzailearekin ukan dezaketen komunztadurari begiratzen badiogu: 


\section{Ricardo Etxepare}
a. Nor etorri da/dira?
b. Zein ikusi duzu/dituzu?

Zer izenordainak ez dezake numero komunztadurarik izan laguntzailearekin:
a. *Zer ikusi dituzu?
b. *Zer gertatu dira?

Zer-dun formek izenezko osagarri bat dutelarik bakarrik (hau da, determinatzaile gisa ari direlarik) eragin dezakete pluraleko komunztadura:

$$
\text { Zer liburu leituko dituzu udaran? }
$$

Hor ere, determinatzailea, gutxi ikerturiko hertsidura zenbaiten jatorrian aurkitzen da. Determinatzaile gisa agertzen den zer formak ez du edozein izenezko osagarri onartzen, edo egiten badu, areagoko baldintzekin egiten du. Euskarazko Ereduzko Korpusean egindako bilaketa batek, zer gehi gizon (izen biziduna) hurrenkerak bilatzeko eginak, moeta jakin bateko aleak ematen ditu bakarrik: zer laguntzen duen izenkiak beti tipo edo klase adiera du. Maiz asko izenkia bera klase edo tipo sailkatzaile batez lagundua agertzen da:

\section{Zer gizon klasek egiten du hori?}

(Paul Auster, Brooklyn Follies, Oskar Aranaren itzulpena)

Litekeena da beraz, zer bezalako determinatzaile batek koertzioz izenen interpretazioa tipoak denotatzen dituzten entitateen aldera bideratzea. Nor/zein eta zer-en arteko diferentzia hori ez da euskararen bitxikeria, baizik eta modu batean edo bestean hizkuntz tipologian ezaguna eta are ikertua (Idiatov, 2007) ere den zerbait. NZ-hitz guziek ez dute ber gauza denotatzen, eta diferentzia horiek biziduntasunaren eta zenbagarritasunaren eskalan kokatzen dira orohar. Heim (1989), aspaldiko lan batean, antzeko ondorioetara iritsi zen ingelesezko what izenordainarentzat, berak "x generoko zerbait" bezala interpretatzea proposatzen zuena. Euskarazko zer izenordainak tipoak denotatzeko joera badu, eta zenbagarritasunaren eskalan behean bada (gogora komunztadura datuak), ez da harritzekoa distribuzioa bideratzen duen egitura batean (zenbagarritasuna baitezpadakoa duena) distribuzio giltza gisa agertzeko zailtasunak izatea. Zailtasun horiek semantikoak dira, eta zer-en denotazioarekin zuzenean lotuak dira.

Honen guziaren ondorio gisa dugu beraz euskarazko zer nork hurrenkeren ezina ez datorrela goragotasun baldintzaren efektuetarik, baizik eta zer izenordainak distribuzioaren giltza gisa jokatzeko duen ezinetik, ezin semantikoa. Euskarazko galdera anizkunek, parekako interpretazioa behartzen dutenean, galdera egituretatik aparte lekukotzen den egitura distributibo baten gainean altxatuak dira. Ustezko goragotasun efektua, zer NZ-hitza lehen elementu gisa duten hurrenkeretara mugatua, horren ondorio da. 


\section{Ricardo Etxepare}

\section{Ondorioak}

Euskarazko NZ-hitz askotako perpausak esplikatzeko orain arteko analisibideek Konplementatzaile Sintagmarako edo Galdegai Sintagmarako mugimendua baliatu izan dute, beste hizkuntzetarako proposatu izan diren analisien bidetik (hala Reglero, 2003 edo Jeong, 2007). Analisi horietako aztergai ezin-utzizko bat da euskarak goragotasun baldintzarekiko erakusten duen portaera nahasia: goragotasun baldintza bortxatzen duten ordenuak posible dira NZ-hitz bizidunekin; ez ordea zer bezalako NZ-hitzekin. Lan honetan entseiatu naiz erakustera galdera anizkunen artean, parekatze galderak deitu ditudanak paralelismo semantiko eta sintaktiko nabarmenak erakusten dituztela berez galderatakoak ez diren beste egitura batzuekin. Egitura horiek NZ izenordain baten gainean altxaturiko distribuzio egiturak dira. Egitura horietan ere, hertsidura bereziak badira distribuzio giltza era dezaketen NZ izenordainei dagokienez: NZ izenordain bizidunak, hala nola nor edo zein, posible dira; zer bezalako bizigabeak berriz ez. Paralelismo horietan (eta bestetan) oinarriturik, proposatu dut parekatze galderen azpiko egitura sintaktikoa distribuzio egitura horiena dela, gehi galderazko indarra eransteko beharrezkoa den sintaxi hezurdura. Analisi honek bestela esplikatzeko gaitzak diren propietate zenbaiten gaineko argia egiten du, hala nola parekatze galderetan bigarren NZ-hitzak erakusten dituen hertsidura semantiko zorrotzak, edo lehen galdera hitzak erakusten dituen muga hertsiak jasan dezakeen konplexutasun sintaktikoari buruz. Euskarazko parekatze galderek zenbatzaile/NZ-hitz interakzioetan nabarmendu izan diren erantzun funtzionalekiko duten loturak perspektiba orokor berritzaileak ekartzen ditu galderen eta distribuzioaren semantikaren arteko harremanen ikerketari dagokionean, eta harreman hauek ukan ditzaketen azpiko amankomuneko propietateetan.

\section{Bibliografia}

Baker, C.L. (1970) "Notes on the description of English questions: the role of an abstract question morpheme" Foundations of Language 6-2: 197-219.

Boeckx, C. eta K. Grohmann (arg) (2003) Multiple Wh-Fronting. Amsterdam: John Benjamins.

Boškovic, Ž. (1998) “Multiple Wh-Fronting and Economy of Derivation”. In Borer, H. (arg) Proceedings of the West Coast Conference on Formal Linguistics 16: 49-63. Stanford, Calif.: Stanford University.

Boškovic, Ž. (1999) "On multiple feature-checking: Multiple wh-fronting and multiple headmovement”. In S. Epstein \& N. Hornstein (arg) Working Minimalism. Cambridge, Mass.: MIT Press. 159-187.

Boškovic, Željko (2000) “Sometimes in Spec CP, sometimes in-situ”. In R. Martin, D. Michaels \& J. Uriagereka (arg) Step by step: Essays on minimalism in honor of Howard Lasnik. Cambridge, Mass.: MIT Press. 53-87 


\section{Ricardo Etxepare}

Boškovic, Ž. (2001) On the nature of the syntax-phonology interface: Cliticization and other phenomena. Amsterdam: Elsevier.

Boškovic, Ž. (2002) “On multiple wh-fronting”. Linguistic Inquiry 33: 351-383.

Bresnan, J. (1972) Theory of Complementation in English Syntax. MIT dissertation.

Brody, M. and A. Szabolcsi (2003) “Overt Scope in Hungarian” Syntax 6-1: 19-52.

Cable, S. (2010) The Grammar of Q. Q-Particles, Wh-Movement and Pied-Piping. Oxford: Oxford University Press.

Chernova, E. (2014) The Syntax of Wh-Movement in Multiple (True and Echo) Questions: a Qparticle Approach. Universitat de Girona dissertation.

Chierchia, Gennaro (1993) "Questions with quantifiers" Natural Language Semantics 1 (2):181-234.

Chomsky, N. (1973) "Conditions on Transformations" in S. Anderson eta P. Kiparsky (arg) A Festschrift for Morris Halle. New York: Holt, Rinehart and Winston. 232-286.

Chomsky, Noam (2000) "Minimalist inquiries: the framework" In Roger Martin, David Michaels and Juan Uriagereka (eds.) Step by Step: Essays on Minimalist Syntax in Honor of Howard Lasnik. Cambridge, Mass: MIT Press. 89-155.

Chomsky, N. (2001) "Derivation by Phase" In M. Kenstowicz (ed) Ken Hale: a Life in Language. Cambridge: MIT Press. 1-52.

Dayal, V. (1996) Locality in Wh-Quantification. Kluwer.

Dukova-Zheleva, G. (2010) Questions and Focus in Bulgarian. University of Ottawa dissertation.

Engdahl, E. (1986) Constituent Questions: the Syntax and Semantics of Questions with Special Reference to Swedish. Springer.

Etxepare, R. (2002) "Bare indefinites and distributivity in Basque" In X. Artiagoitia, P. Goenaga and J. A. Lakarra (eds) Erramu Boneta. Festschrift for Rudolf P.G. De Rijk. Bilbao: University of the Basque Country. 231-246.

Etxepare, R. (agertzekoa) "Wh-distributives in Basque" In A. Gallego eta D. Ott (arg) Cartography and Explanatory Adequacy. Oxford: Oxford University Press.

Etxepare, R. and J. Ortiz de Urbina (2003) “Focalization" In J. I. Hualde and J. Ortiz de Urbina (eds) A Grammar of Basque. Berlin: Mouton de Gruyter. 459-514. 


\section{Ricardo Etxepare}

Groenendijk, J. and M. Stokhof (1984) Studies in the Semantics of Questions and the Pragmatics of Answers. Doctoral dissertation, University of Amsterdam.

Heim, I. (1987) "Where does the definiteness restriction apply? Evidence from the definiteness of variables" In E. Reuland and A.Ter Meulen (eds.) The Representation of (In)definiteness. Current studies in Linguistics 14, MIT Press, pp. 21-42.

Hornstein, N. (1995) Logical Form. From GB to Minimalism. Blackwell.

Horvath, J. (1986) Focus in the Theory of Grammar and the Syntax of Hungarian. Foris: Dordrecht.

Idiatov, D. (2007) A Typology of Non-Selective Pronominals. Doctoral Dissertation, University of Antwerp.

Jeong, Y. (2007) «Multiple wh-fronting in Basque » In A. Conroy, C. Jing, C. Nakao eta E. Takahashi (arg), University of Maryland Working Papers in Linguistics 15. 98-142.

Kitahara, H. (1997) Elementary Operations and Optimal Derivations. Cambridge: MIT Press.

Lahiri, U. (2002) Questions and Answers in Embedded Contexts. Oxford: Oxford University Press.

Ortiz de Urbina, J. (1989) Parameters in the Grammar of Basque. Dordrecht: Foris.

Reglero, L. (2003) "Non Wh-fronting in Basque" In K. Grohmann and C. Boeckx (eds) Multiple Wh-Fronting. Amsterdam: John Benjamins. 187-227.

Reglero, L. (2004) "Preguntas multiples en euskara” ASJU 38-1: 249-285

Richards, N. (2001) Movement in Language. Interactions and Architectures. Oxford: Oxford University Press.

Rizzi, L. (1997) “The fine structure of the left periphery”. In L. Haegeman (ed.) Elements of grammar. Dordrecht: Kluwer. 281-337.

Rooth, M. (1992) “A Theory of Focus Interpretation” Natural Language Semantics 1: 75-116.

Rudin, C. (1988) "On Multiple Questions and Multiple Fronting" Natural Language and Linguistic Theory 6: 445-501.

Suñer, M. (1993) “About Indirect questions and semi-questions" Linguistics and Philosophy 16-1: 45-77.

Szabolcsi, A. (2010) Quantification. Cambridge University Press. 


\section{Ricardo Etxepare}

Vicente, L. (2013) "On the causes of superiority effects in Spanish: Preliminary results and prospects" Catalan Journal of Linguistics 12: 283-300.

Wachowicz, K. (1974) "Against the Universality of a Single Wh-Question Movement" Foundations of Language 11-2:155-166.

Yatsushiro, K. (2009) "The distribution of quantificational suffixes in Japanese" Natural Language Semantics 17: 141-173. 